\title{
Effect of the Wnt/ $\beta$-catenin pathway inhibitors on cell proliferation and migration of HEC-1A endometrial adenocarcinoma: experimental cell culture model
}

\author{
Yaşam Çirçirci®, R. Nalan Tiftik®, İsmail Ün® \\ Department of Medical Pharmacology, Mersin University School of Medicine, Mersin, Turkey
}

\begin{abstract}
Objectives: The most diagnosed tumor among infiltrating tumors of the female genital tract is endometrial carcinoma. The Wnt/ $\beta$-catenin signaling pathway has an important role in organogenesis, self-renewal of tissues, and adult stem cell maintenance. However aberrant activation of it causes many types of tumors and also related to the prognosis of patients. Therefore, we aimed to investigate whether $\mathrm{Wnt} / \beta$-catenin pathway inhibitors have any effect on the proliferation and migration of tumor cells.

Methods: As cancer cell line, HEC-1A endometrial adenocarcinoma was used. The Wnt/ $\beta$-catenin pathway inhibitors effects on proliferation and migration were demonstrated by real-time cell analysis device and wound healing model respectively.

Results: Wnt $/ \beta$-catenin pathway inhibitors FH535 (25 $\mu \mathrm{M}$ at $36^{\text {th }}$ hour, $p<0.05 ; 50 \mu \mathrm{M}$ at $48^{\text {th }}$ hour $\left.p<0.001\right)$ and niclosamide inhibited cell proliferation $\left(10,25\right.$ and $50 \mu \mathrm{M}$ at $60^{\text {th }}$ hours; $p<0.01, p<0.05$ and $p<0.001$, respectively) whereas ICRT14 and IWP-2 did not. However only niclosamide which is also an antihelmintic drug inhibited migration of the cells in all concentrations tested $(10,25$ and $50 \mu \mathrm{M}, p<0.05)$.

Conclusions: The present study shows that the $\mathrm{Wnt} / \beta$-catenin pathway has an substantial role in both proliferation and migration of endometrial adenocarcinoma. We suggest that the antihelmintic drug niclosamide could be further investigated for its potential therapeutic effect in endometrial adenocarcinoma.

Keywords: Wnt/ $\beta$-catenin, endometrial adenocarcinoma, niclosamide, migration
\end{abstract}

$\mathrm{n}$ the female genital tract most frequent infiltrating tumor is endometrial carcinoma which mostly occurs in the postmenopausal age $[1,2]$. Endometrial cancers are mainly diagnosed at early stages, and 5year of survival is between $20 \%$ to $91 \%$ depending on the stage. Hormone therapy, older age, exercise, diet and, diabetes are risk factors for developing endometrial cancer [3].

The Wnt/ $\beta$-catenin signaling pathway has important roles in organogenesis, development, adult stem cell functions, and renewal of tissues. However abnormal activation of it causes many types of tumors [4, $5]$. It has been reported that mutations of the $\beta$-catenin gene result in endometrial tumorigenesis [6-8]. Besides malignant transformation and tumor progression also proposed to require activation of the pathway [9]. Estrogens could induce Wnt/ $\beta$-catenin signaling and may cause endometrial hyperplasia even cancer. In contrast, progesterone was suggested as an inhibitor of this signaling [9]. This pathway also have coopera- 
tive with other pathways such as cyclooxygenase, EGFR signaling and Notch signaling [10].

In endometriosis patients inhibition of $\mathrm{Wnt} / \beta$-catenin signaling reported to prevent migration, invasion and proliferation, of epithelial and stromal cells of [10].

Although $\mathrm{Wnt} / \beta$-catenin signaling inhibitors have not yet been in clinical practice for endometrial cancer treatment, experimental data have promising consequences [9]. Wnt/ $\beta$-catenin signaling pathway has a substantial role in cell proliferation, migration and cell fate specification, [10]. HEC-1A cells are experimental models for postmenopausal endometrial cancer and it enables investigations for regulatory and signaling mechanisms $[11,12]$. Therefore, we aimed to investigate whether $\mathrm{Wnt} / \beta$-catenin signaling inhibitors have any effect on the proliferation and migration of HEC1A endometrial adenocarcinoma cells.

\section{METHODS}

\section{Cell Line}

HEC-1A which is a human originated endometrial carcinoma and often used as an experimental model for type 2 postmenopausal endometrial cancers was used as a cell culture (provide from ATCC $^{\circledR}$ HTB$112^{\mathrm{TM}}$ ). $10 \%$ fetal bovine serum (Biological Industries USA) 1\% Penicillin/streptomycin (Biological Industries USA), L-glutamine (PAN-Biotech, Germany) were added to McCoy's 5A (Lonza, US) and served as medium for cells. The incubator was adjusted to $5 \%$ $\mathrm{CO}_{2}$ at $37^{\circ} \mathrm{C}$. Cells were getting confluent approximately in 10-14 days and had a 95-99\% viability rate. Cells that were contaminated or had phenotypic changes were excluded from the study.

\section{Preparation of Drugs}

Wnt/ $\beta$-catenin pathway inhibitors FH535, ICRT14, IWP-2, and niclosamide were purchased from Sigma-Aldrich, USAFH535, ICRT14, IWP-2, and niclosamide $(10,25$, and $50 \mu \mathrm{M}$ each) were dissolved in the $0.5 \%$ dimethyl sulfoxide (DMSO). The data recorded from the migrations and proliferation with Wnt/ $\beta$-catenin pathway inhibitors were compared against control group (DMSO 0.5\%).

\section{Proliferation Studies}

The effect of the Wnt/ $\beta$-catenin pathway inhibitors on proliferation was recorded by real-time cell analysis (xCELLigence) device. The xCELLigence is used for real-time monitoring of cell proliferation. It enables recording of electronic impedance of E-Plates. Each well of the E-plate were seeded with 10000 cells and incubated for 24 hours. Thereafter Wnt/ $\beta$-catenin pathway inhibitors FH535, ICRT14, IWP-2, and niclosamide $(10,25$, and $50 \mu \mathrm{M}$ each) were added to the wells. E-plates were put into the incubator which also contains the device.

\section{Migration Model}

The wound healing model used for migration studies. Each well of 24 well plate were seeded with 30000 cells. When cells were reach to confluency after approximately 10 days they were incubated with serumfree medium for 24 hours. Thereafter, by using a 20 $\mu l$ pipette the wound lines were opened on cells that grown on plates. After the administration of $1 \%$ FBS medium to wells, FH535, ICRT14, IWP-2, and niclosamide $(10,25$, and $50 \mu \mathrm{M}$ each) were applied. After the inhibitor agent administration $(t=0)$ and subsequently at $24^{\text {th }}$ and $48^{\text {th }}$ hours, the wound images were measured. Relative cell motility was calculated by the formula (wound width at $\mathrm{t}=0$ hours) - (wound width at $\mathrm{t}=24$ or 48 hours).

\section{Statistical Analysis}

Cell proliferation obtained from xCELLingence system was expressed as cell index "CI" and CI $>0.2$ was considered as positive. Data were presented as mean \pm SEM. One-way analysis of variance and post hoc Bonferroni test was used for statistical evaluation or t-test were used when appropriate. A $P$ value smaller than 0.05 was considered significant.

\section{RESULTS}

\section{The Effect of DMSO on Cell Proliferation and Migra-} tion

Following the incubation cells were gradually proliferated in both saline and DMSO groups (Fig. 1a). The concentrations of DMSO in both E-plate wells and migration wells were $0.5 \%$ and did change neither cell proliferation (Fig. 1a, $p>0.05$ ) nor cell migration (Fig. 1b, $p>0.05$ ). 

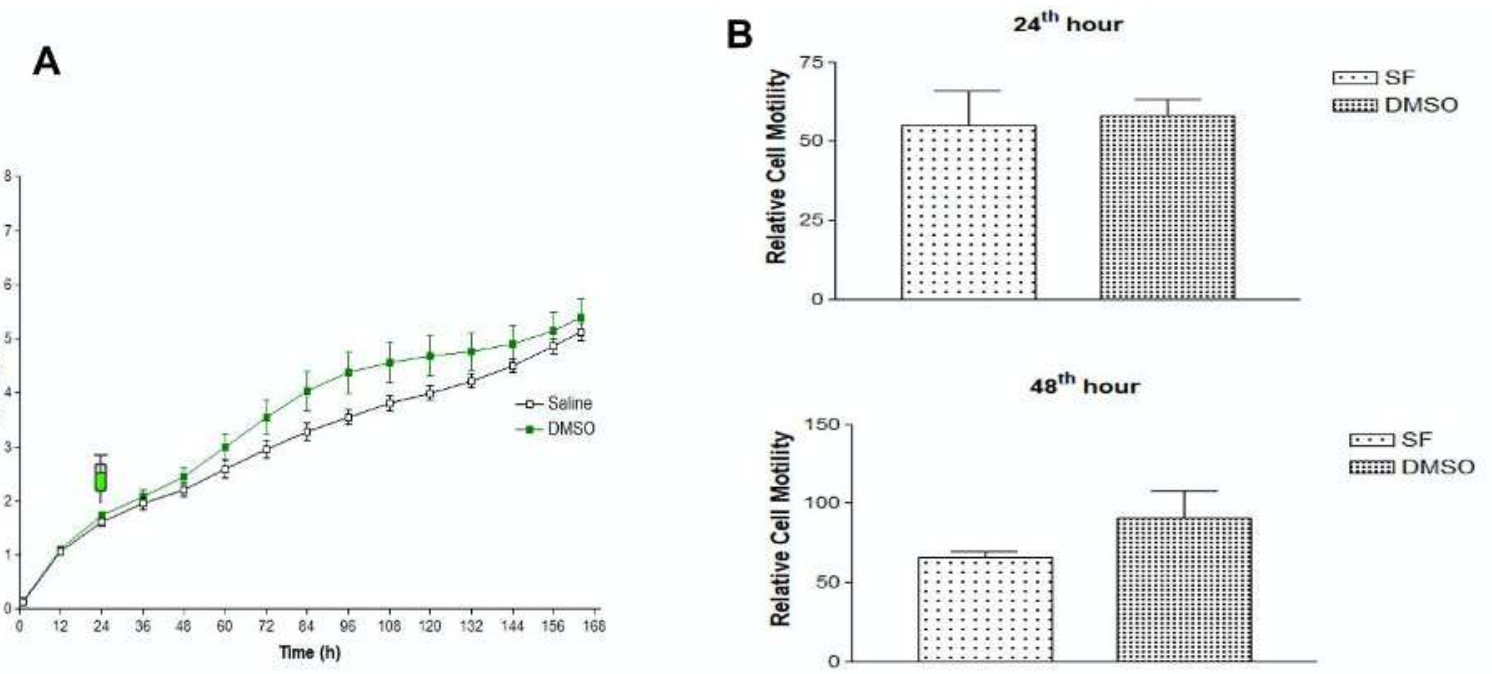

Fig. 1. Effect of DMSO (vehicle) on the proliferation (a) and migration (b) of HEC1A cells by real-time cell analysis and

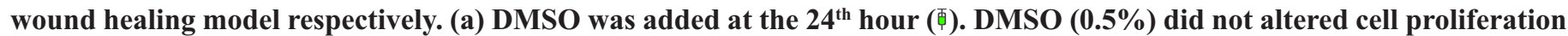
$(n=4)(p>0.05)$. (b) Treatments were made at the 0th hour for migration. The concentration of DMSO was $0.5 \%$ in wells and did not change cell migration $(p>0.05)$.

\section{The Effect of FH535 on Cell Proliferation and Migra-} tion

$10 \mu \mathrm{M}$ of FH535 did not change cell proliferation (Fig. $2 \mathrm{a}, p>0.05$ ). $25 \mu \mathrm{M}$ of FH535 starts to inhibit cell proliferation 12 (36th hour on the graph) hours after the application (Fig. $2 \mathrm{a}, p<0.05$ ). $25 \mu \mathrm{M}$ of FH535 decreased proliferation between the 36th and $84^{\text {th }}$ hours and after the $84^{\text {th }}$ hours started to cause cell death (Fig. 2a, $p<0.001$ ). The higher $50 \mu \mathrm{M}$ concentrations of FH535 start to cause cell death at earlier times between the $48^{\text {th }}$ and $168^{\text {th }}$ hours (Fig. $2 \mathrm{a}, p<$ $0.001)$. However FH535 did not change the cell migration of HEC-1A cells (Fig. 2b, $p>0.05$ ).

A

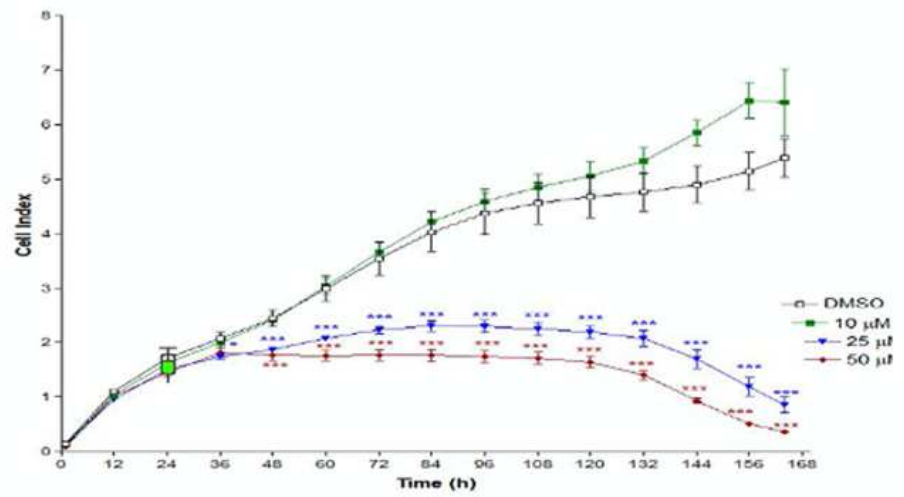

The Effect of ICRT14 on Cell Proliferation and Migration

10,25 , and $50 \mu \mathrm{M}$ of ICRT14 did not change cell proliferation of endometrial adenocarcinoma HEC-1A cells (Fig. 3a). ICRT14 did not change the cell migration of HEC-1A cells (Fig. 3b, $p>0.05$ ).

The Effect of IWP-2 on Cell Proliferation and Migration

10,25 , and $50 \mu \mathrm{M}$ of IWP-2 did not change cell proliferation of endometrial adenocarcinoma HEC-1A cells (Fig. 4a). IWP-2 did not change the cell migration of HEC-1A cells (Fig. 4b, $p>0.05$ ).
B

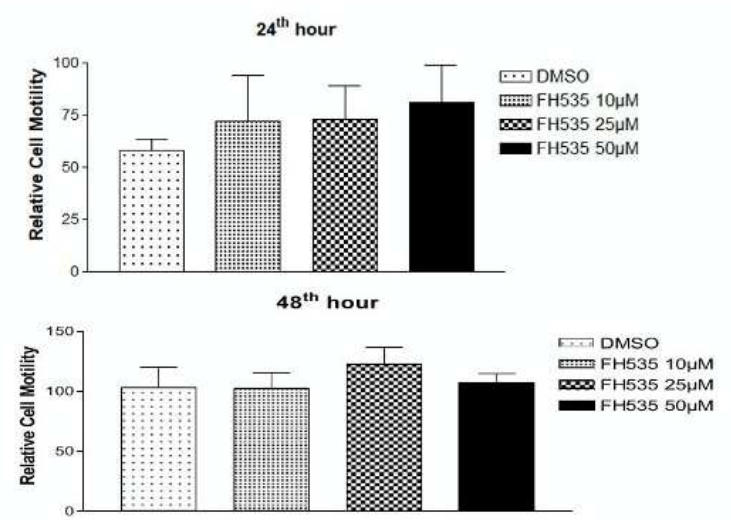

Fig. 2. The effect of FH535 on cell proliferation (a) and migration (b). (a) Treatments were made at the $24^{\text {th }}$ hour (画) for proliferation.10 $\mu$ M of FH535 did not change cell proliferation. $25 \mu \mathrm{M}$ of FH535 started to inhibit cell proliferation at $36^{\text {th }}$ hour. $25 \mu \mathrm{M}$ of FH535 decreased proliferation between the $36^{\text {th }}$ and $84^{\text {th }}$ hours and after the $84^{\text {th }}$ hours started to cause cell death. $50 \mu \mathrm{M}$ concentrations of FH535 start to cause cell death at earlier times between the $48^{\text {th }}$ and $168^{\text {th }}$ hours $(* p<0.05, * * * p<$ 0.001). (b) Treatments were made at the $0^{\text {th }}$ hour for migration. FH535 did not change the cell migration of HEC-1A cells ( $p$ $>$ 0.05). 
A

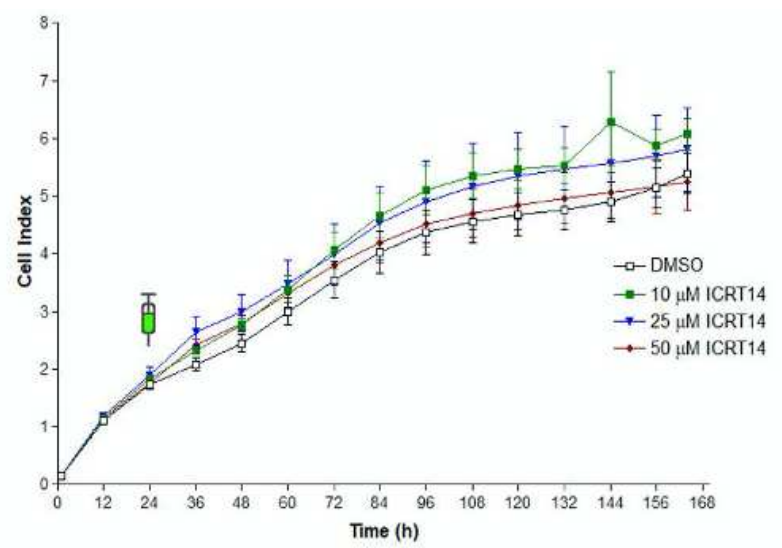

B
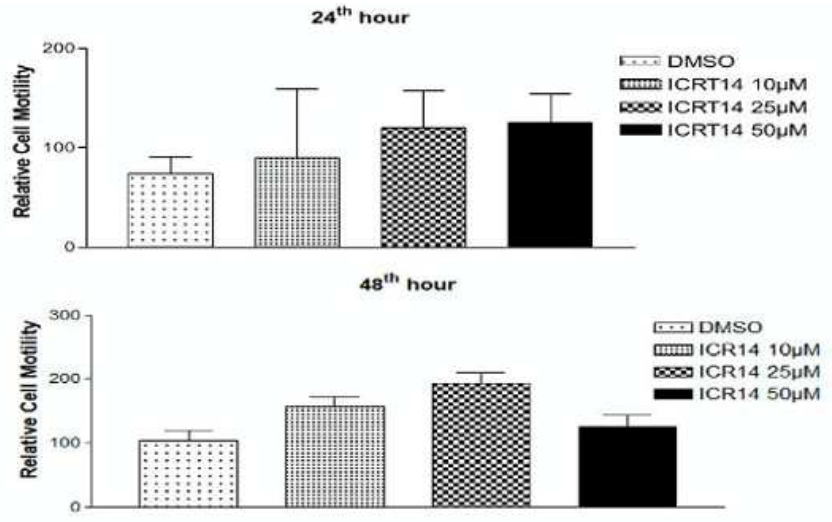

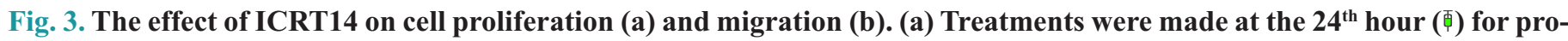
liferation. 10, 25, and 50 $\mu \mathrm{M}$ of ICRT14 did not change cell proliferation of endometrial adenocarcinoma HEC-1A cells. (b) Treatments were made at the $\mathbf{0}^{\text {th }}$ hour for migration. ICRT14 did not change the cell migration of HEC-1A cells $(p>0.05)$.

A

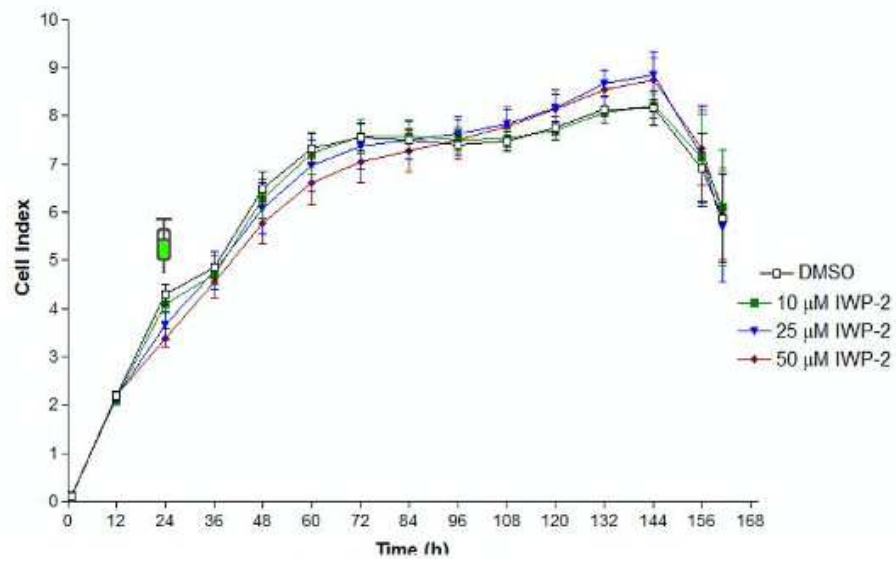

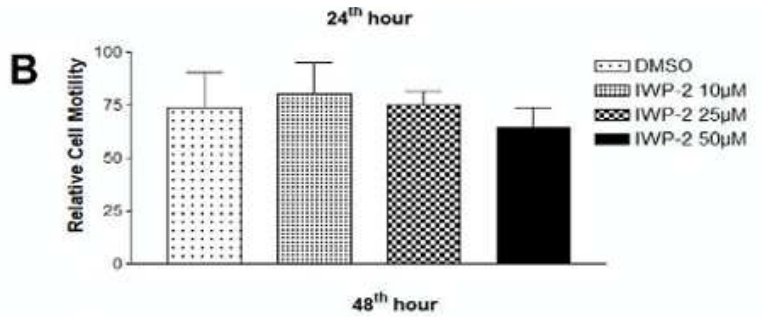

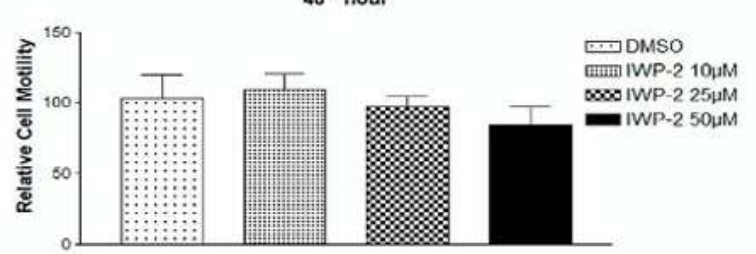

Fig. 4. The effect of IWP-2 on cell proliferation (a) and migration (b). (a) Treatments were made at the $24^{\text {th }}$ hour (画) for proliferation. 10, 25, and 50 $\mu \mathrm{M}$ of IWP-2 did not change cell proliferation of endometrial adenocarcinoma HEC-1A cells. (b) Treatments were made at the $0^{\text {th }}$ hour for migration. IWP-2 did not change the cell migration of HEC-1A cells $(p>0.05)$.

A

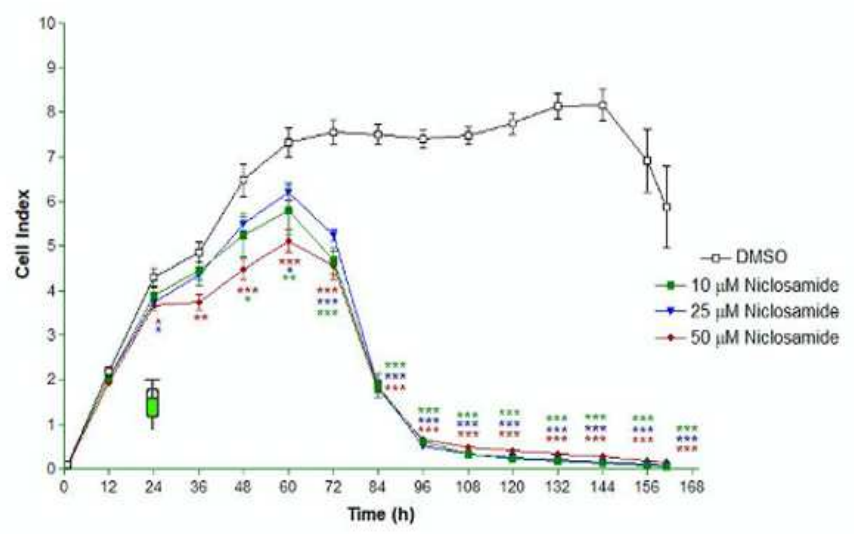

B
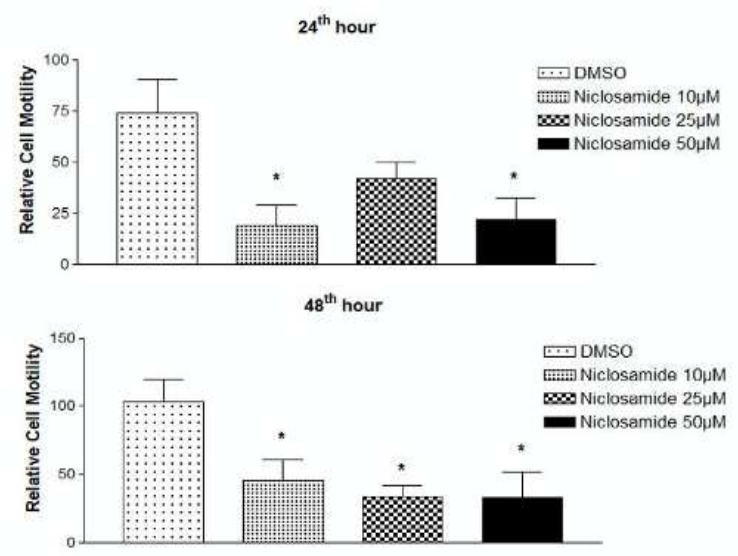

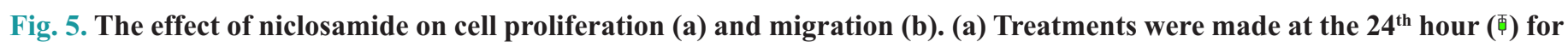
proliferation. 10, 25, and 50 $\mu \mathrm{M}$ of niclosamide inhibited cell proliferation. While the effect of 25 and $50 \mu \mathrm{M}$ of niclosamide started immediately after the application, the effect of $10 \mu \mathrm{M}$ observed at $48^{\text {th }}$ hour. After the $60^{\text {th }}$ hour there was a fast decrease in cell index with al concentrations used $(* p<0.05, * * * p<0.001)$. (b) Treatments were made at the $0^{\text {th }}$ hour for migration. Niclosamide significantly inhibited cell migration of HEC-1A cells at all concentrations tested $(p<0.05)$. 
The Effect of Niclosamide on Cell Proliferation and Migration

10,25 , and $50 \mu \mathrm{M}$ of niclosamide inhibited cell proliferation. While the effect of 25 and $50 \mu \mathrm{M}$ of niclosamide started immediately after the application, the effect of $10 \mu \mathrm{M}$ observed at $48^{\text {th }}$ hour. After the $60^{\text {th }}$ hour, there was a fast decrease in cell index with all concentrations used (Fig. 5a). Niclosamide significantly inhibited cell migration of HEC-1A cells at all concentrations tested (Fig. 5b, $p<0.05$ ).

\section{DISCUSSION}

The effects of four Wnt/ $\beta$-catenin pathway inhibitors on cell proliferation and migration that are important for cancer prognosis were tested in HEC-1A cells which are being used an experimental model for type 2 postmenopausal endometrial cancers [12]. Wnt/ $\beta$-catenin pathway inhibitors, FH535, and niclosamide inhibited cell proliferation whereas ICRT14 and IWP-2 did not. However, only niclosamide which is also an antihelmintic drug inhibited migration of the cells.

FH535 is a cell-permeable sulfonamide compound that inhibits $\beta$-catenin-Tcf/LEF interaction in the Wnt/ $\beta$-catenin pathway but also suppresses the Peroxisome Proliferator-Activated Receptor $(\operatorname{PPAR} \gamma / \delta)$ signal. PPARs belong to the nuclear receptor protein group and act as transcription factors that regulate the gene expression [13].

In hepatocellular carcinoma cells, FH535 suppressed the proliferation, and $50 \mu \mathrm{M}$ significantly reduced the distance between the two lines in the wound healing test [14]. It has been reported that FH535 inhibited cell proliferation $(10 \mu \mathrm{M}, 20 \mu \mathrm{M}$, and $40 \mu \mathrm{m})$ and migration at 24 hours in wound healing experiment $(20 \mu \mathrm{M}$ and $40 \mu \mathrm{M})$ in colon cancer cell lines [15]. In another study, the effect of FH535 on pancreatic cell lines were examined (PANC-1 and BXPC-3), and $20 \mu \mathrm{M}$ FH535 concentration did not change the expression of $\beta$-catenin in BXPC-3 cells but decreased the expression of $\beta$-catenin in PANC-1 cells. In the wound healing experiment, the $20 \mu \mathrm{M}$ concentration of FH535 significantly reduced migration at 8 and 12 hours [16]. Also, it has been reported that FH535 inhibits proliferation at concentrations of $0.1 \mu \mathrm{M}, 1 \mu \mathrm{M}$, and $10 \mu \mathrm{M}$ in osteosarcoma cells [17]. The antiprolif- erative effect observed in hepatocellular carcinoma cells with the addition of FH535 at $50 \mu \mathrm{M}$ concentration is similar to our study, but the antiproliferative effect observed in colorectal cancer cells with the addition of FH535 at $10 \mu \mathrm{M}$ concentration was not noticed in HEC1A cells. Besides, inhibition of migration in the wound healing experiment in hepatocellular carcinoma, colorectal cancer, pancreas, and osteosarcoma cells was not observed in HEC1A cells. Different effects observed in the same concentration in the cell lines suggested that the inhibitory action of FH535 may change depending on the cell type.

In our study, the $25 \mu \mathrm{M}$ concentration of FH535 reduced proliferation starting from the 24 th hour, as well as reducing the number of cells after the 84th hour. $50 \mu \mathrm{M}$ concentrations of FH535 tend to decrease proliferation after 12 hours and started to decrease the number of cells after 24 hours. Niclosamide administration reduced proliferation from the first moment of administration and additionally decreased the number of cells after $36^{\text {th }}$ hour at all concentrations. In this study, cell death mechanisms have not been studied, but we suggest that the decrease in the number of cells at the specified hours may be related to the activation of cell death mechanisms. Because the cells in the control group at the same time were still growing at their normal rate.

Niclosamide inhibits the co-receptor LRP6 via increasing the Wnt receptor Fzd1 internalization, inhibits Dv12 expression via inhibiting the $\beta$-catenin/TCF complex formation, and thereby inhibits the Wnt/ $\beta$-catenin signaling at multiple levels. In addition, niclosamide also inhibits Notch, STAT, $3 \mathrm{NF}-\kappa \mathrm{B}$, and mTORC1signaling pathways. At the same time it may induce growth inhibition, apoptosis and cell cycle arrest via targeting the mitochondria of cancer cells. [18].

Gyamfi et al. [19] have shown that niclosamide inhibits both proliferation and migration in breast cancer cell lines. Arend et al. [20] showed antiproliferative effects of it in ovarian cancer cells $(0.1-4 \mu \mathrm{M})$. Zhao et al. [21] have demonstrated that it inhibits proliferation in renal cell carcinoma lines. Wang et al. [22] showed that it inhibits proliferation in hepatocellular cell lines, induces apoptosis, and increases the cisplatin sensitivity of cancer cells. Liu et al. [23] reported that $0.1 \mu \mathrm{M}, 0.25 \mu \mathrm{M}$, and $0.5 \mu \mathrm{M}$ niclosamide suppress cell migration in prostate cancer cells. Li et 
al. [24] have demonstrated that different concentrations of niclosamide between $0.1 \mu \mathrm{M}-10 \mu \mathrm{M}$ in human osteosarcoma cell lines inhibit cell proliferation by stopping the cell cycle. Likewise in our study niclosamide prevented both proliferation and migration in endometrium adenocarcinoma HEC1A cells. Among other inhibitors tested in this study, only niclosamide inhibited migration. Based on this finding, it could be suggested that this effect by niclosamide is due to a nonspecific effect of it rather than the Wnt/ $\beta$-catenin pathway inhibition. However, further and detailed molecular studies are needed to confirm this suggestion. One of the limitations of this study is that expression and activation studies have not been performed for the Wnt / $\beta$-catenin pathway.

ICRT14 belongs to the thiazolidinedione class of $\beta$-catenin responsive transcription inhibitors, and also prevents TCF binding to DNA [13]. In one study, ICRT14 has been shown to induce significant G0/G1 cell cycle arrest in colon cancer cell lines, and in another study, increased sensitivity to chemotherapy in pediatric acute lymphocytic leukemia patients by inhibiting Wnt $[25,26]$. IWP-2 blocks Wnt production by directly inhibiting the porcupine active site, it can also affect $\mathrm{CK} 1 \delta / \varepsilon$ related pathways [27]. Kleszcz et al. [28] have demonstrated that IWP-2 inhibits porcupine, reducing the Wnt signal, thereby inducing apoptosis in neck and head carcinoma cells. Tong et al. [29] showed that artemisinin derivatives can significantly inhibit tumor metastasis and lung tumorigenesis via Wnt/ $\beta$-catenin signaling. In our study, ICRT14 and IWP2 did not change proliferation and migration at the concentration and time intervals tested.

\section{CONCLUSION}

In this study, we examined the possible effects of $\mathrm{Wnt} / \beta$-catenin pathway inhibitors on proliferation and migration in endometrial adenocarcinoma HEC1A cells, which are important parameters for cancer. We have shown that FH535 inhibits proliferation, and niclosamide both proliferation and migration. We suggest that antihelmintic drug niclosamide which is a cheap antiparasitic drug could be regarded as a potential therapeutic agent in endometrium adenocarcinoma. Further studies on the effects of niclosamide and its derivatives on proliferation and migration and other parameters of cancer are needed to elucidate the pathogenesis of endometrial cancers, prevent progression of the disease and develop new treatment strategies.

\section{Authors' Contribution}

Study Conception: YÇ, İÜ; Study Design: YÇ, RNT, IÜ; Supervision: IÜ̈; Funding: İ̈̈; Materials: İÜ, RNT; Data Collection and/or Processing: YÇ, RNT, IÜ; Statistical Analysis and/or Data Interpretation: YÇ, RNT, İÜ; Literature Review: YÇ, İ̈̈; Manuscript Preparation: İ̈, RNT and Critical Review: İ̈, RNT.

\section{Conflict of interest}

The authors disclosed no conflict of interest during the preparation or publication of this manuscript.

\section{Financing}

The University Scientific Research Projects Center supported this work (project number: 2018-2-TP23022)

\section{REFERENCES}

1. Pillozzi S, Fortunato A, Lorenzo ED, Borrani E, Giachi M, Scarselli G, et al. Over-expression of the LH receptor increases distant metastases in an endometrial cancer mouse model. Front Oncol 2013;3:285.

2. Antovska VS, Krstevska I, Trajanova M, Chelebieva J, Gosheva I, Zdravkovski P, et al. Endometrioid Adenocarcinoma Arising in Adenomyoma in a Woman with a Genital ProlapseCase Report. Open Access Maced J Med Sci 2018;14:1091-4.

3. Morice P, Leary A, Creutzberg C, Abu-Rustum N, Darai E. Endometrial cancer. Lancet 2016;12:1094-1108.

4. Mac Donald BT, Tamai K, He X. Wnt/b-catenin signaling: components, mechanisms, and diseases. Dev Cell 2009;17:9-26. 5. White BD, Chien AJ, Dawson DW. Dysregulation of Wnt/bcatenin signaling in gastrointestinal cancers. Gastroenterology 2012;142:219-32.

6. Kobayashi K, Sagae S, Nishioka Y, Tokino T, Kudo R. Mutations of the beta catenin gene in endometrial carcinomas. Jpn J Cancer Res 1999;90:55-9.

7. Fukuchi T, Sakamoto M, Tsuda H, Maruyama K, Nozawa S, Hirohashi S. Beta-catenin mutation in carcinoma of the uterine endometrium. Cancer Res 1998;58:3526-28.

8. Saegusa M, Hashimura M, Yoshida T, Okayasu I. beta- Catenin mutations and aberrant nuclear expression during endometrial tumorigenesis. Br J Cancer 2001;84:209-17.

9. Wang Y, van der Zee M, Fodde R, Blok LJ. Wnt/B-catenin and sex hormone signaling in endometrial homeostasis and cancer. Oncotarget 2010;1:674-84. 
10. Polakis P. Wnt signaling in cancer. Cold Spring Harb Perspect Biol 2012;4:a008052.

11. Matsuzaki S, Darcha C. In vitro effects of a small-molecule antagonist of the Tcf/sscatenin complex on endometrial and endometriotic cells of patients with endometriosis. PLoS One. 2013;8:e61690.

12. Hevir-Kene N, Rižner TL. The endometrial cancer cell lines Ishikawa and HEC-1A, and the control cell line HIEEC, differ in expression of estrogen biosynthetic and metabolic genes, and in androstenedione and estrone-sulfate metabolism. Chem Biol Interact 2015;234:309-19.

13. Handeli S, Simon JA. A small-molecule inhibitor of Tcf/betacatenin signaling down-regulates PPARgamma and PPARdelta activities. Mol Cancer Ther 2008;7:521-9.

14. Tomizawa M, Shinozaki F, Hasegawa R, Shirai Y, Motoyoshi Y, Sugiyama T, et al. Immunosuppressive agents are associated with peptic ulcer bleeding. Exp Ther Med 2017;13:1927-31.

15. Chen Y, Rao X, Huang K, Jiang X, Wang H, Teng L. FH535 Inhibits proliferation and motility of colon cancer cells by targeting Wnt/ $\beta$-catenin signaling pathway. J Cancer 2017;8:3142-53. 16. Wu MY, Liang RR, Chen K, Shen M, Tian YL, Li DM, et al. FH535 inhibited metastasis and growth of pancreatic cancer cells. Onco Targets Ther 2015;8:1651-70.

17. Gustafson CT, Mamo T, Shogren KL, Maran A, Yaszemski MJ. FH535 Suppresses Osteosarcoma Growth In Vitro and Inhibits Wnt Signaling through Tankyrases. Front Pharmacol 2017;8:285.

18. Li Y, Li PK, Roberts MJ, Arend RC, Samant RS, Buchsbaum DJ. Multi-targeted therapy of cancer by niclosamide: a new application for an old drug. Cancer Letters 2014;349:8-14.

19. Gyamfi J, Lee YH, Min BS, Choi J. Niclosamide reverses adipocyte induced epithelial-mesenchymal transition in breast cancer cells via suppression of the interleukin-6/STAT3 signalling axis. Sci Rep 2019;9:11336.

20. Arend RC, Londoño-Joshi AI, Gangrade A, Katre AA, Kurpad C, Li Y, et al. Niclosamide and its analogs are potent in- hibitors of Wnt/ $\beta$-catenin, mTOR and STAT3 signaling in ovarian cancer. Oncotarget 2016;7:86803-15.

21. Zhao J, He Q, Gong Z, Chen S, Cui L. Niclosamide suppresses renal cell carcinoma by inhibiting Wnt/ $\beta$-catenin and inducing mitochondrial dysfunctions. Springerplus 2016;5:1436. 22. Wang C, Zhou X, Xu H, Shi X, Zhao J, Yang M, et al. Niclosamide inhibits cell growth and enhances drug sensitivity of hepatocellular carcinoma cells via STAT3 signaling pathway. J Cancer 2018;9:4150-55.

23. Liu C, Lou W, Armstrong C, Zhu Y, Evans CP, Gao AC. Niclosamide suppresses cell migration and invasion in enzalutamide resistant prostate cancer cells via Stat3-AR axis inhibition. Prostate 2015;75:1341-53.

24. Li Z, Yu Y, Sun S, Qi B, Wang W, Yu A. Niclosamide inhibits the proliferation of human osteosarcoma cell lines by inducing apoptosis and cell cycle arrest. Oncol Rep 2015;3:1763-8.

25. Gonsalves FC, Klein K, Carson BB, Katz S, Ekas LA, Evans S. An RNAi-based chemical genetic screen identifies three smallmolecule inhibitors of the Wnt/wingless signaling pathway. Proc Natl Acad Sci U S A 2011;108:5954-63.

26. Dandekar S, Romanos-Sirakis E, Pais F, Bhatla T, Jones C, Bourgeois W, et al. Wnt inhibition leads to improved chemosensitivity in paediatric acute lymphoblastic leukaemia. Br J Haematol 2014; 167:87-99.

27. García-Reyes B, Witt L, Jansen B, Karasu E, Gehring T, Leban J, et al. Discovery of inhibitor of Wnt production 2 (IWP2) and related compounds as selective ATP-competitive inhibitors of casein kinase 1 (CK1) $\delta / \varepsilon$. J Med Chem 2018;61:4087-102.

28. Kleszcz R, Szymańska A, Krajka-Kuźniak V, Baer-Dubowska $\mathrm{W}$, Paluszczak J. Inhibition of $\mathrm{CBP} / \beta$-catenin and porcupine attenuates Wnt signaling and induces apoptosis in head and neck carcinoma cells. Cell Oncol (Dordr) 2019;42:505-20.

29. Tong Y, Liu Y, Zheng H, Zheng L, Liu W, Wu J, et al. Artemisinin and its derivatives can significantly inhibit lung tumorigenesis and tumor metastasis through $\mathrm{Wnt} / \beta$-catenin signaling. Oncotarget 2016;7:31413-28. 